\title{
Sodalis gen. nov. and Sodalis glossinidius sp. nov., a microaerophilic secondary endosymbiont of the tsetse fly Glossina morsitans morsitans
}

\author{
Colin Dale $†$ and Ian Maudlin
}

Author for correspondence: Colin Dale. Tel: +44 1904 434383. Fax: +44 1904434383. e-mail: cd15@york.ac.uk

Division of Molecular Genetics, University of Glasgow, Glasgow G11 6NU, UK

\begin{abstract}
A secondary intracellular symbiotic bacterium was isolated from the haemolymph of the tsetse fly Glossina morsitans morsitans and cultured in Aedes albopictus cell line $\mathrm{C6/36}$. Pure-culture isolation of this bacterium was achieved through the use of solid-phase culture under a microaerobic atmosphere. After isolation of strain $\mathrm{M1}^{\top}$, a range of tests was performed to determine the phenotypic properties of this bacterium. Considering the results of these tests, along with the phylogenetic position of this micro-organism, it is proposed that this intracellular symbiont from $\mathbf{G}$. m. morsitans should be classified in a new genus Sodalis gen. nov., as Sodalis glossinidius gen. nov., sp. nov. Strain M1 $^{\top}$ is the type strain for this new species.
\end{abstract}

Keywords: Sodalis glossinidius gen. nov., sp. nov., insect endosymbiont, tsetse, microaerophile

\section{INTRODUCTION}

Endosymbiotic bacteria are found in a wide range of insect taxa, where they provide supplementary nutritional components essential for the survival of insects that feed on a restricted diet such as plant sap or blood (Buchner, 1965; Douglas, 1989). Many of these micro-organisms have proved reluctant to yield to conventional culture techniques; currently a trivial nomenclature system is in use to provide a distinction between different types of insect endosymbiont. This distinction is recognized on the basis of host tissue distribution, with 'primary $(\mathrm{P})$ endosymbionts' residing exclusively within a single (specialized) cell type and 'secondary (S) endosymbionts' residing in multiple host tissues. While phylogenetic analysis has proved useful for determining the taxonomic position of several insect endosymbionts (Aksoy, 1995; Beard et al., 1993b; Campbell et al., 1992; Clark et al., 1992; Hypsa \& Dale, 1997; Hypsa \& Aksoy, 1997; Munson et al., 1991; O'Neill et al., 1992, 1993; Unterman et al., 1989) these fastidious bacteria have proved refractory to conventional culture techniques and consequently

† Present address: Department of Biology, University of York, Heslington, York Y01 5rW, UK.

Abbreviations: $M M$, Mitsuhashi-Maramorosch; $P$, primary; S, secondary. only a handful of specimens have been assigned correct nomenclature (Aksoy, 1995; Hypsa \& Dale, 1997; Munson et al., 1991).

In the tsetse fly (Glossina spp.) P-and S-endosymbionts coexist in the gut lumen, with P-endosymbionts occupying specialized mycetocyte cells in the anterior portion of the insect gut and S-endosymbionts occupying midgut epithelial cells (Huebner \& Davey, 1974; Pinnock \& Hess, 1974). While the role of each micro-organism has not been clearly defined, collectively their presence is known to be essential for egg production and larval development in the insect (Nogge, 1981). Elimination of the bacterial endosymbionts with antibiotics, lysozyme and specific antibodies leads to reproductive abnormalities and growth retardation in the aposymbiotic host (Hill \& Campbell, 1973; Nogge, 1976, 1978; Pinnock \& Hess, 1974; Southwood et al., 1975). While the P- and Sendosymbionts of tsetse flies are both members of the family Enterobacteriaceae ( $\gamma$ subclass of the class Proteobacteria), each endosymbiont forms a distinct lineage within the family Enterobacteriaceae, sharing high $16 \mathrm{~S}$ rDNA sequence identity with $\mathrm{P}$ - and Sendosymbionts found in other insects (Aksoy et al., 1995). Only the P-endosymbionts show concordant evolution with their insect host, having 16S rDNA sequences which mirror the evolution of the Glossina 
complex (Aksoy et al., 1997). Tsetse S-endosymbionts isolated from different Glossina spp. share almost identical 16S rDNA sequences, suggesting recent acquisition of these organisms and possible horizontal symbiont transfer (Aksoy et al., 1997).

The multi-tissue S-endosymbionts of tsetse flies were the first true insect endosymbionts to be cultivated in vitro. This was achieved through the use of a mosquito (Aedes albopictus) feeder cell culture system (Welburn et al., 1987), which has recently been used for the cultivation of other fastidious insect bacteria (Hypsa \& Dale, 1997; O'Neill et al., 1997). Tsetse fly S-endosymbionts have recently been cultivated in cell-free media, although solid-phase culture and pure culture has not been achieved (Beard et al., 1993b). The cultivation of tsetse fly S-endosymbionts has provoked interest in the use of these micro-organisms as potential tools for engineering refractory arthropod disease vectors, incapable of transmitting parasitic trypanosomes (Aldhous, 1993; Beard et al., 1993a). Since tsetse fly S-endosymbionts are located in the insect gut where incoming parasites arrive, they may provide an excellent platform for anti-parasite gene expression. In addition, the $\mathrm{S}$-endosymbionts of tsetse flies have been proposed to play an important role in the acquisition of trypanosome infections in tsetse flies, with their presence in certain fly lines promoting susceptibility to trypanosome infection (Maudlin \& Ellis, 1985).

In this study we describe the isolation and pure culture of an S-endosymbiont from the haemolymph of $G . m$. morsitans. This was achieved by culture on a semidefined solid medium under microaerobic conditions. In addition, we present the results of the phenotypic tests that are required for the valid description of this new bacterial taxon and species. Considering the phylogenetic position and the results of the phenotypic tests we formally propose that the S-endosymbiont of G. m. morsitans should be classified in a new genus, Sodalis gen. nov., and in a new species, Sodalis glossinidius gen. nov., sp. nov.

\section{METHODS}

Isolation and cultivation of the G. m. morsitans Sendosymbiont in an insect cell line. The $G . m$. morsitans Sendosymbiont culture used for this study was isolated from a laboratory colony of $G$. m. morsitans (Tsetse Research Group, University of Glasgow, UK). Aedes albopictus cell line C6/36 (Igarashi, 1978) was maintained in MitsuhashiMaramorosch (MM) medium (ICN Biomedicals) supplemented with $20 \%(\mathrm{v} / \mathrm{v})$ heat-inactivated foetal calf serum at $25^{\circ} \mathrm{C}$ by passaging the cells every $10 \mathrm{~d}$ with a $1: 10$ split into fresh MM medium. Five adult G. $m$. morsitans were surface sterilized by immersion in Alcide LD (Life Science Laboratories) for $5 \mathrm{~min}$ and rinsed twice in sterile water. Haemolymph was collected in a sterile capillary tube after puncturing each fly in the fons region with a sterile needle. Immediately after collection, the haemolymph was mixed with $200 \mu \mathrm{l}$ MM medium. The coverslip technique (Welburn et al., 1987) was used to enhance infection of the confluent Aedes albopictus cell culture by centrifugation as follows. After mixing the $200 \mu \mathrm{lMM} /$ haemolymph with $5 \mathrm{ml} 48 \mathrm{~h}$ - old C6/36 cells (cultivated on a coverslip in a flat-bottomed centrifuge tube), the cultures was centrifuged $(1500 \mathrm{~g}, 5 \mathrm{~min}$, $25^{\circ} \mathrm{C}$ ) to promote bacterial colonization of the insect cells. Infected cultures were maintained at $25^{\circ} \mathrm{C}$ and passaged every $3 \mathrm{~d}$ by inoculating a fresh $\mathrm{C} 6 / 36$ culture with a $1 / 10$ volume of symbiont-infected $\mathrm{C} 6 / 36$ cells. The Gimenez staining procedure (Gimenez, 1964) was used to examine the morphology of the cultured S-endosymbiont.

Solid-phase culture of the S-endosymbiont on agar media containing aerotolerance-enhancing supplements. Basal MM agar was prepared from serum-free MM medium by the addition of bacto-agar (Difco) to $1 \%$ (w/v). After autoclaving and cooling to $50^{\circ} \mathrm{C}$, aliquots of basal MM agar were supplemented with the following aerotoleranceenhancing supplements: Activated charcoal $\left(10 \mathrm{mg} \mathrm{ml} \mathrm{m}^{-1}\right.$; Sigma), bovine catalase (10, 100 and $1000 \mathrm{U} \mathrm{ml}^{-1}$; Sigma), $\mathrm{FeSO}_{4}\left(5,10\right.$ and $50 \mathrm{mg} \mathrm{ml}^{-1}$; Sigma), dithioerythritol (1, 5 and $10 \mathrm{mg} \mathrm{ml}^{-1}$; Sigma) and fresh horse red blood cells $(2 \mathrm{ml}$ packed red cells mixed with $8 \mathrm{ml}$ MM medium; Tissue Culture Services). Plates containing supplemented MM agar were inoculated with $200 \mu$ symbiont-infected $\mathrm{C} 6 / 36$ culture fluid and maintained at $25^{\circ} \mathrm{C}$.

Solid-phase culture of the Sendosymbiont on MM agar under different atmospheres. Basal MM agar plates were inoculated with $200 \mu 1$ symbiont-infected C6/36 culture fluid and maintained at $25^{\circ} \mathrm{C}$ under a range of different atmospheres in gas jars (Oxoid) at $25^{\circ} \mathrm{C}$. Anaerobic conditions were created by the action of an anaerobic catalyst (Oxoid), which was activated and maintained in a sealed jar along with inoculated MM agar plates. Microaerobic and aerobic conditions were created by flushing sealed gas jars (containing inoculated plates) with 100 vols appropriate gas mixture. The gas mixtures employed in the experiment were $5,10,15$ and $20 \%$ oxygen balanced with either carbon dioxide or nitrogen. As a control treatment, a single inoculated plate was maintained in a gas jar filled with air.

Isolation of strain $\mathrm{M1}^{\top}$, a pure culture isolate of S-endosymbiont. Strain $\mathrm{M1}^{\mathrm{T}}$ was obtained by the isolation of a single S-endosymbiont colony from an MM agar plate after $7 \mathrm{~d}$ growth in a microaerobic atmosphere $\left(5 \% \mathrm{O}_{2}\right.$, balanced with $\mathrm{CO}_{2}$ ) at $25^{\circ} \mathrm{C}$. Strain $\mathrm{M} 1^{\mathrm{T}}$ was used for all subsequent experiments described in this study.

Detection of the Sendosymbiont by PCR. Primers GP01F ( $5^{\prime}$ TGAGAGGTTCGTCAATGA $3^{\prime}$ ) and GP01R (5' ACGCTGCGTGACCATTC 3') were used for the detection of Sendosymbionts, as these primers are known to amplify a $1 \cdot 2 \mathrm{~kb}$ fragment of an abundant extrachromosomal element found in this bacterium (O'Neill et al., 1993). The single colony used for the isolation of strain $\mathrm{M}^{\mathrm{T}}$ was resuspended in $50 \mu \mathrm{l} \mathrm{MM}$ medium and $5 \mu \mathrm{l}$ of this cell suspension was used as template for PCR with primers GP01F and GP01R. Samples $(1 \mu \mathrm{l})$ of culture fluid from $\mathrm{S}$-endosymbiont-infected and uninfected $\mathrm{C} 6 / 36$ cell cultures were used as template in positive and negative control PCRs (respectively) using the same primer set $(\mathrm{GP01F} / \mathrm{R})$. PCRs were carried out in $50 \mu 1$ thermostable polymerase buffer (Promega) containing $1.5 \mathrm{mM} \mathrm{MgCl}_{2}, 0.2 \mathrm{mM}$ dNTPs, $20 \mathrm{pmol}$ each primer and 1 U Taq DNA polymerase (Promega). Reaction conditions consisted of an initial $5 \mathrm{~min}$ denaturation step $\left(94^{\circ} \mathrm{C}\right)$ followed by 35 cycles of denaturation $\left(94^{\circ} \mathrm{C}, 1 \mathrm{~min}\right)$, annealing $\left(55^{\circ} \mathrm{C}, 1 \mathrm{~min}\right)$ and extension $\left(72^{\circ} \mathrm{C}, 1 \mathrm{~min}\right)$.

Cloning and sequencing of $16 \mathrm{~S}$ rDNA from strain $\mathrm{M1}^{\top}$. One microlitre of strain $M 1^{\mathrm{T}}$ cell suspension was used as template for a PCR with conserved primers 5' GCTTAACACATGCAAG $3^{\prime}$ and 5' ACGGGCAGTGTGTACAAGACC 
$3^{\prime}$, which are known to amplify a $1361 \mathrm{bp}$ fragment of $16 \mathrm{~S}$ rDNA (O'Neill et al., 1993). PCRs with the 16S rDNA consensus primers (including two negative-control reactions with no template) were carried out as outlined above for the GP01F/R primer set, using identical cycling parameters and reaction components, except for the primers. To facilitate Atailing and subsequent cloning, the PCR program included an additional final $10 \mathrm{~min}$ extension step $\left(72{ }^{\circ} \mathrm{C}\right)$. The $1361 \mathrm{bp}$ PCR product obtained from strain $\mathrm{M} 1^{\mathrm{T}}$ was cloned into T-tailed pBS SK + (Stratagene) and recombinant plasmids were sequenced by the chain-termination method on an Applied Biosystems automated sequencer.

Identification of strain $\mathrm{M}^{\top}$ by extrachromosomal DNA profile analysis. To confirm the identity of strain $M 1^{\mathrm{T}}$, the remaining $45 \mu \mathrm{l}$ of the single colony isolate suspension was inoculated into $25 \mathrm{ml} \mathrm{MM}$ medium and incubated at $25^{\circ} \mathrm{C}$. After $7 \mathrm{~d}$ growth, $20 \mathrm{ml}$ culture medium was removed and the bacteria were pelleted by centrifugation $(5000 \mathrm{~g}, 5 \mathrm{~min})$. Extrachromosomal DNA was prepared using a Wizard Minipreps plasmid DNA purification kit (Promega) according to the manufacturer's instructions with the following modifications: plasmid DNA was eluted from the column with $50 \mu \mathrm{l}$ sterile water, which had been heated to $80^{\circ} \mathrm{C}$ in a water bath prior to application onto the column. After elution into an Eppendorf, the aqueous DNA solution was combined with loading buffer and absorbed onto small squares of sterile Whatman No. 1 paper, to prevent shearing prior to electrophoresis. Extrachromosomal DNA was also prepared from S-endosymbionts cultivated in C6/36 cells following an identical procedure after removal of the C6/36 cells by low speed centrifugation $(500 \mathrm{~g}, 10 \mathrm{~min})$. Both extrachromosomal DNA preparations were resolved by overnight electrophoresis $\left(1 \mathrm{~V} \mathrm{~cm}^{-1}\right)$ through a $0.6 \%(\mathrm{w} / \mathrm{v})$ agarose gel.

Phenotypic tests. The remaining $5 \mathrm{ml}$ of the $\mathrm{M} 1^{\mathrm{T}}$ culture used for extrachromosomal DNA preparation was streaked onto MM agar plates and incubated under a microaerobic atmosphere to provide material for a range of phenotypic tests. Phenotypic tests were conducted using diagnostic tablets (Rosco Diagnostica) following the manufacturer's instructions with the exception that the enzymic reactions were incubated at the optimum growth temperature for Sendosymbionts $\left(25^{\circ} \mathrm{C}\right)$. Reactions were permitted to continue for twice the normal time before scoring to account for reduced enzyme activity at this temperature. Where diagnostic tablets were not applicable, tests were conducted according to established procedures (Cowan, 1974), again at $25^{\circ} \mathrm{C}$ using an extended incubation period. To ensure the validity of the test procedures control tests were conducted under identical conditions using Escherichia coli K12, Citrobacter freundii ATCC 10787 and Xenorhabdus nematophilus ATCC 19061. All phenotypic tests were conducted under both aerobic and microaerophilic conditions.

Carbon substrate assimilation tests. Since no minimal medium has been reported for the culture of Glossina Sendosymbionts, strain $\mathrm{M}^{\mathrm{T}}$ carbon substrate assimilation tests were conducted during culture in the semi-defined MM medium prepared without the addition of glucose. For testing, $10 \mu \mathrm{l}$ of a suspension of strain Ml in glucose-free MM medium was inoculated into culture tubes containing $10 \mathrm{ml}$ MM medium supplemented (individually) to $2 \%$ $(\mathrm{w} / \mathrm{v})$ with the carbon sources outlined in Table 2. For comparison, $10 \mu \mathrm{l}$ of the same suspension of strain $\mathrm{M} 1^{\mathrm{T}}$ was inoculated into $10 \mathrm{ml}$ glucose-free MM medium without any carbon supplement present. To assess carbon source utili- zation, the increase in turbidity of each culture was determined by spectrophotometry after $7 \mathrm{~d}$ incubation at $25^{\circ} \mathrm{C}$ by measuring $\mathrm{OD}_{600}$ using a Corning spectrophotometer. Acid production was detected by repeating the carbon substrate assimilation tests with identical culture media containing the indicators phenol red (for detection of weak acid production) and bromcresol green (for detection of strong acid production). All tests were conducted under microaerobic conditions.

\section{RESULTS AND DISCUSSION}

\section{Culture of the Sendosymbiont in Aedes albopictus cell line $\mathrm{C} 6 / 36$}

Pleiomorphic, rod-shaped bacteria were visible in Aedes albopictus $\mathrm{C} 6 / 36$ cells at $24 \mathrm{~h}$ following inoculation with insect haemolymph. At this time, most of the bacteria observed were bound to the surface of C6/36 cells, forming small nests of infection. As the infection progressed, bacteria were observed penetrating the surface of the insect cells and dividing within the cell cytosol ( $48 \mathrm{~h}$ post-inoculation). By $72 \mathrm{~h}$ postinoculation, bacterial infection was widespread with many insect cells displaying extensive intracellular infection (Fig. 1). The course and timing of the bacterial infection cycle was identical to that observed previously for Glossina S-endosymbionts cultivated in C6/36 cells (Welburn et al., 1987).

\section{Microaerobic culture of the Sendosymbiont}

A solid-phase MM agar culture system was used to investigate the aerotolerance of the cultured S-endosymbiont. Chemical and enzyme supplements, known

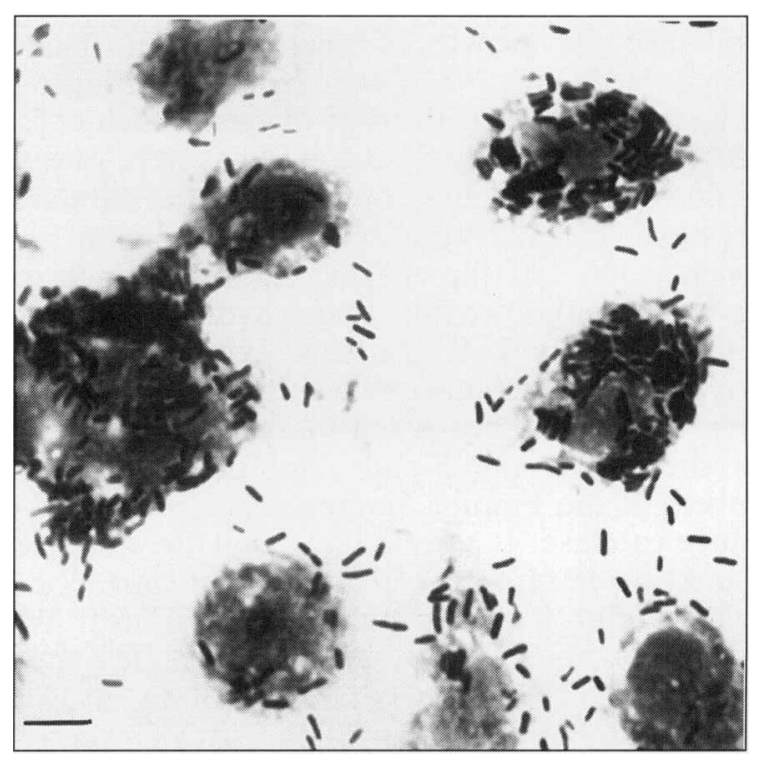

Fig. 1. Light micrograph of Aedes albopictus C6/36 cells, $72 \mathrm{~h}$ after inoculation of haemolymph from G. m. morsitans. At this stage the insect cells display extensive intracellular infection. Bar, $5 \mu \mathrm{m}$. 
Table 1. Aerotolerance of the G. m. morsitans S-endosymbiont

- , No growth; w, colony diameter $<0.5 \mathrm{~mm} ;+$, colony diameter $0.5-1 \mathrm{~mm} ;++$, colony diameter $>1 \mathrm{~mm}$.

\begin{tabular}{|c|c|c|c|c|c|c|c|c|c|c|}
\hline \multirow{2}{*}{$\begin{array}{c}\text { Supplement/atmosphere } \\
\text { Days post } \\
\text { inoculation ... }\end{array}$} & \multicolumn{10}{|c|}{ Growth } \\
\hline & 1 & 2 & 3 & 4 & 5 & 6 & 7 & 8 & 9 & 10 \\
\hline Control (air) & - & - & - & - & - & - & - & - & - & - \\
\hline $10 \mathrm{mg}$ charcoal $\mathrm{ml}^{-1}$ & - & - & - & - & - & - & - & - & - & - \\
\hline $10 U_{\text {catalase }} \mathrm{ml}^{-1}$ & - & - & - & - & - & $\mathrm{w}$ & w & $\mathrm{w}$ & w & $\mathrm{w}$ \\
\hline $100 \mathrm{U}$ catalase $\mathrm{ml}^{-1}$ & - & - & - & w & + & + & + & + & + & + \\
\hline $1000 \mathrm{U}$ catalase $\mathrm{ml}^{-1}$ & - & - & - & w & + & + & + & + & + & + \\
\hline $5 \mathrm{mg} \mathrm{FeSO}_{4} \mathrm{ml}^{-1}$ & - & - & - & - & - & - & - & - & - & - \\
\hline $10 \mathrm{mg} \mathrm{FeSO}_{4} \mathrm{ml}^{-1}$ & - & - & - & - & - & - & - & - & - & - \\
\hline $50 \mathrm{mg} \mathrm{FeSO}_{4} \mathrm{ml}^{-1}$ & - & - & - & - & - & - & - & - & - & - \\
\hline $2 \mathrm{mg} \mathrm{KMnO}_{4} \mathrm{ml}^{-1}$ & - & - & - & - & - & - & - & - & - & - \\
\hline $10 \mathrm{mg} \mathrm{KMnO}{ }_{4} \mathrm{ml}^{-1}$ & - & - & - & - & - & - & - & - & - & - \\
\hline $20 \mathrm{mg} \mathrm{KMnO}_{4} \mathrm{ml}^{-1}$ & - & - & - & - & - & - & - & - & - & - \\
\hline $1 \mathrm{mg}$ dithioerythritol $\mathrm{ml}^{-1}$ & - & - & - & - & - & - & - & - & - & - \\
\hline $5 \mathrm{mg}$ dithioerythritol $\mathrm{ml}^{-1}$ & - & - & - & - & - & - & - & - & - & - \\
\hline $10 \mathrm{mg}$ dithioerythritol $\mathrm{ml}^{-1}$ & - & - & - & - & - & - & - & - & - & - \\
\hline $\begin{array}{l}20 \% \text { packed horse red } \\
\text { blood cells }\end{array}$ & - & - & - & $\mathrm{w}$ & + & ++ & ++ & ++ & ++ & ++ \\
\hline $20 \% \mathrm{O}_{2} / 80 \% \mathrm{~N}_{2}$ & - & - & - & - & - & - & - & - & - & - \\
\hline $15 \% \mathrm{O}_{2} / 85 \% \mathrm{~N}_{2}$ & - & - & - & - & - & - & - & - & - & - \\
\hline $10 \% \mathrm{O}_{2} / 90 \% \mathrm{~N}_{2}^{2}$ & - & - & - & $\mathrm{w}$ & $\mathrm{w}$ & $\mathrm{w}$ & $\mathrm{w}$ & $\mathrm{w}$ & $\mathrm{w}$ & $\mathrm{w}$ \\
\hline $5 \% \mathrm{O}_{2} / 95 \% \mathrm{~N}_{2}$ & - & - & - & w & + & + & + & + & ++ & ++ \\
\hline $20 \% \mathrm{O}_{2} / 80 \% \mathrm{CO}_{2}$ & - & - & - & - & - & - & - & - & - & - \\
\hline $15 \% \mathrm{O}_{2} / 85 \% \mathrm{CO}_{2}$ & - & - & - & - & - & - & - & - & - & - \\
\hline $10 \% \mathrm{O}_{2} / 90 \% \mathrm{CO}_{2}$ & - & - & - & $w$ & + & + & + & + & ++ & ++ \\
\hline $5 \% \mathrm{O}_{2} / 95 \% \mathrm{CO}_{2}$ & - & - & - & + & ++ & ++ & ++ & ++ & ++ & ++ \\
\hline Anaerobic catalyst & - & - & - & - & - & - & w & $\mathrm{w}$ & w & w \\
\hline
\end{tabular}

to enhance the growth of microaerophilic bacteria (Krieg \& Hoffman, 1986), were incorporated into test media to examine the effects of oxygen toxicity (Table 1). After $5 \mathrm{~d}$ growth at $25^{\circ} \mathrm{C}$, colonies were observed only on MM agar plates containing either catalase or fresh horse blood. Fresh blood is known to be an excellent source of the enzyme catalase, which catalyses the breakdown of toxic hydrogen peroxide (Bolton et al., 1984). In this experiment the Sendosymbiont grew most efficiently on media supplemented with fresh horse red blood cells. Phenotypic tests show that the S-endosymbiont, unlike most members of the Family Enterobacteriaceae, does not produce catalase. It seems likely that the absence of this enzyme is responsible, at least in part, for the restricted aerotolerance of this micro-organism. While growth was observed on MM agar plates supplemented with blood or catalase, colony size was irregular. At the beginning of the streak, where the inoculum was heavy, growth was dense and confluent with large colonies developing and merging. At the end of a streak, where the inoculum was thin, growth was sparse with colonies only attaining a small diameter. The subculture of individual colonies onto fresh plates showed that colony morphology did not breed true, indicating that mutation or phase-variation were unlikely to be responsible for the irregular colony sizes observed. Population-dependent growth has been observed with a number of other microaerophilic bacteria whose growth rate often increases with total respiratory capacity (Krieg \& Hoffman, 1986).

Synthetic gas mixtures were used to determine the effect of atmospheric oxygen and carbon dioxide availability on the solid-phase culture of the Sendosymbiont (Table 1). After $5 \mathrm{~d}$ at $25^{\circ} \mathrm{C}$, bacterial growth was observed only on $\mathrm{MM}$ agar plates incubated in atmospheres containing $<10 \%$ oxygen, confirming that atmospheric oxygen inhibits the growth of the S-endosymbiont on solid media. While these bacteria grew very poorly in an anaerobic atmosphere, the presence of $5 \%$ oxygen greatly stimulated growth. In addition, growth was enhanced by the presence of carbon dioxide, a gas known to enhance the growth of a number of other microaerophiles, including Campylobacter spp. (Krieg \& Hoffman, 1986). Carbon dioxide utilization is a feature of bacteria which employ an anapleurotic cycle for the 
enzymic replenishment of tricarboxylic acid cycle intermediates that are used up during biosynthetic reactions (Moat \& Foster, 1988). This is of some interest in the context of insect-bacterial symbioses where certain insect symbionts are known to assist their insect host through the provision of essential dietary factors lacking in the host's natural diet (Douglas, 1989). While there is no direct evidence of a biosynthetic capability in Glossina S-endosymbionts, it is known that the P-endosymbionts of aphids (including Buchnera aphidicola) supplement the insect host via the provision of essential amino acids which are lacking in the host's natural diet of plant sap (Douglas, 1997). In such a system, carbon dioxide fixation and assimilation by the anapleurotic cycle would certainly provide a means of replacing intermediates used up during the biosynthesis of nitrogenous compounds.

To our knowledge, this is the first example of successful insect S-endosymbiont culture on an agar-based medium. With increasing interest in the possibility of using insect symbionts to express anti-parasitic gene products in insect disease vectors (Aldhous, 1993), this new culture technique will permit the application of modern microbial genetic procedures requiring a solidphase culture system. In addition a solid-phase culture system may prove useful for the isolation and cultivation of symbiotic bacteria from other insects.

\section{Isolation of strain $\mathrm{M1}^{\top}$, a pure culture isolate of the Sendosymbiont}

Bacterial strain $\mathrm{M}^{\mathrm{T}}$ was obtained by the isolation of a single S-endosymbiont colony from an MM agar plate after $7 \mathrm{~d}$ growth in a microaerobic atmosphere $\left(5 \% \mathrm{O}_{2}\right.$ balanced with $\mathrm{CO}_{2}$ ) at $25^{\circ} \mathrm{C}$. Strain $\mathrm{M}^{1}$ Tas been maintained in our laboratory for two years and was used for all of the subsequent experiments described in this study.

\section{$16 \mathrm{~S}$ rDNA sequence analysis of strain $\mathrm{M1}^{\top}$}

To confirm the identity of $\mathrm{M}^{\mathrm{T}}$, a $1361 \mathrm{bp}$ fragment of the 16S rDNA locus was amplified by PCR using consensus primers (data not shown). Sequencing revealed that the partial $16 \mathrm{~S}$ rDNA sequence obtained from strain $M 1^{T}$ was identical to that obtained in a previous study from the S-endosymbiont of $G . \mathrm{m}$. morsitans (Beard et al., 1993b; GenBank accession number M99060). This data confirms that bacterial strain $\mathrm{Ml}^{\mathrm{T}}$, isolated on solid media, is the S-endosymbiont found in G. m. morsitans.

\section{PCR using primer set GP01F/R}

PCR using the Glossina S-endosymbiont-specific primer set GP01F/R was used to detect strain $\mathrm{Ml}^{\mathrm{T}}$, isolated after solid-phase culture of the S-endosymbiont. The single expected $1.2 \mathrm{~kb}$ PCR product

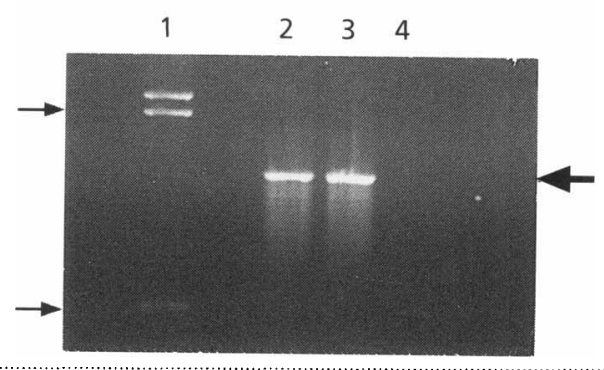

Fig. 2. $P C R$ analysis of strain $M 1^{\top}$ using primer set GPOIF/R. Lane 1, Hindlll-digested lambda DNA markers of 2027 (upper small arrow) and 564 bp (lower small arrow); lane 2, PCR product obtained with strain $M 1^{\top}$ cells used as template; lane 3, PCR carried out with $\mathrm{C6/36-G}$. m. morsitans S-endosymbiont culture fluid used as template; lane 4 , PCR product obtained with uninfected $C 6 / 36$ culture fluid used as template. The large arrow indicates the expected $1.2 \mathrm{~kb}$ PCR product.

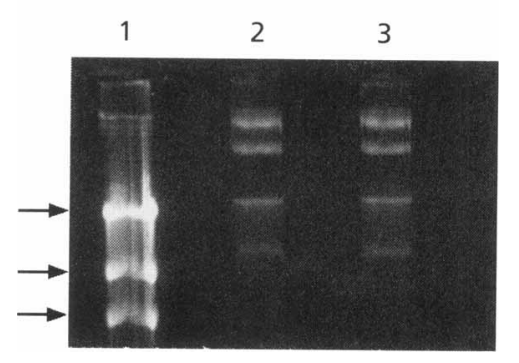

Fig. 3. Extrachromosomal DNA prepared from strain $M 1^{\top}$ and the G. $m$. morsitans S-endosymbiont cultured with Ae. albopictus C6/36 cells. Lane 1, Hindlll-digested lambda DNA markers of 23130 (upper arrow), 9416 (middle arrow) and 6557 bp (lower arrow); lane 2, extrachromosomal DNA prepared from strain $\mathrm{M}^{\top}{ }^{\mathrm{T}}$; lane 3 , extrachromosomal DNA prepared from the G. m. morsitans S-endosymbiont cultured with Ae. albopictus $\mathrm{C} 6 / 36$ cells.

(Fig. 2) was observed in reactions containing cells from strain $\mathrm{M} 1^{\mathrm{T}}$ and the original S-endosymbiont-infected C6/36 culture (depicted in Fig. 1). No product was observed when uninfected $\mathrm{C} 6 / 36$ culture material was used as template for the PCR.

\section{Extrachromosomal DNA analysis of strain $\mathrm{M1}^{\top}$}

Extrachromosomal DNA was prepared from strain $\mathrm{M} 1^{\mathrm{T}}$ and the original S-endosymbiont $\mathrm{C} 6 / 36$ culture (depicted in Fig. 1). Electrophoresis revealed that the extrachromosomal DNA profiles were identical (Fig. 3 ), in addition these profiles matched those obtained in a previous study (Dale, 1997). These individual profiles comprise a number of large extrachromosomal elements and have proved to be diagnostic for Sendosymbionts, permitting differentiation between isolates obtained from different Glossina spp. (Dale, 1997). It is clear that the array of extrachromosomal DNA molecules, which may prove important for 
future symbiont engineering, are maintained through the microaerobic-culture procedure.

\section{Colony morphology of strain $\mathbf{M} \mathbf{1}^{\top}$}

On MM agar plates incubated under a $5 \%$ oxygen, $95 \%$ carbon dioxide atmosphere, strain $\mathrm{M}^{\mathrm{T}}$ displayed uniform colony size and morphology with colonies appearing shiny, off-white and concave with entire edges.

\section{Phenotypic features of strain $\mathrm{M} \mathbf{1}^{\top}$}

The results of the phenotypic tests were found to be identical under aerobic and microaerophilic conditions, and they reveal that strain $\mathrm{M} 1^{\mathrm{T}}$ is characterized by an inactive biochemical profile in comparison with other members of the family Enterobacteriaceae. Strain $\mathrm{M} 1^{\mathrm{T}}$ was non-motile and negative for catalase, oxidase, deoxyribonuclease, gelatinase, urease, nitrate reductase, indole production, hippurate hydrolysis, arginine dihydrolase, lysine decarboxylase, ornithine decarboxylase, phenylalanine deaminase, starch hydrolysis, $\alpha$-fucosidase, $\beta$-galactosidase, $\alpha$-glucosidase, $\beta$-glucosidase, $\beta$-glucuronidase, $\alpha$-mannosidase and $\beta$ xylosidase. Strain $M 1^{\mathrm{T}}$ did produce $\alpha$-galactosidase and $\beta$-N-acetylglucosaminidase. The validity of the test results was confirmed by results obtained with the control bacterial strains (Escherichia coli K12, Citrobacter freundii ATCC 10787 and Xenorhabdus nematophilus ATCC 19061) with all results (data not shown) conforming to those published in Bergey's Manual of Determinative Bacteriology ( 9 th edn). The choice of phenotypic tests for this study was based upon features which are commonly used to differentiate members of the family Enterobacteriaceae (consisting mainly of genera which have been isolated and investigated because of their intrinsic association with animals and humans). Phenotypic testing has so far only been conducted on a few members of the family Enterobacteriaceae known to be associated with insects and this can be attributed to the fastidious nature of these organisms, many of which have not been isolated in pure culture. Of the insect-associated members of the Enterobacteriaceae which are known, phenotypic testing has only been undertaken with members of the genera Xenorhabdus and Photorhabdus, and Arsenophonus nasoniae. In common with strain $\mathrm{M} 1^{\mathrm{T}}$, these three genera all share a relatively inactive biochemical profile in comparison with other members of the family Enterobacteriaceae. However unlike Xenorhabdus spp. and Photorhabdus spp., which are both motile, and Arsenophonus nasoniae, which hydrolyses gelatin, strain $\mathrm{Ml}$ is both non-motile and does not hydrolyse gelatin. Unlike most members of the family Enterobacteriaceae, including Arsenophonus nasoniae and Xenorhabdus luminescens, strain $\mathrm{M}^{\mathrm{T}}$ does not produce catalase, accounting for the microaerophilic nature of this bacterium. It is known from a previous study that the S-endosymbiont produces at least one
Table 2. Carbon substrate assimilation and acid production tests.

\begin{tabular}{|lcc|}
\hline Carbon substrate & Assimilation* & $\begin{array}{c}\text { Acid } \\
\text { production } \dagger\end{array}$ \\
\hline$N$-acetyl-D-glucosamine & + & + \\
Glucose & + & $\mathrm{w}$ \\
Glycol chitosan & + & $\mathrm{w}$ \\
Mannitol & + & $\mathrm{w}$ \\
Raffinose & + & + \\
Sorbitol & + & $\mathrm{w}$ \\
\hline
\end{tabular}

* Positive assimilation indicates a final turbidity reading $>0 \cdot 1$ $\mathrm{OD}_{600}$ units. Assimilation was deemed to be negative when the final $\mathrm{OD}_{600}$ reading was $<0 \cdot 05$. Strain $\mathrm{M1}^{\mathrm{T}}$ was negative for acetic acid, adonitol, $\delta$-amino valeric acid, L-arabinose, nbutanol, citric acid, dulcitol, ethanol, fructose, fumaric acid, galactose, glycerol, glycolic acid, histamine, $p$-hydroxy benzoic acid, $\alpha$-ketoglutaric acid, lactose, D,L-malic acid, maltose, mannose, melibiose, methyl- $\alpha$-D-glucopyranoside, myo-inositol, n-propanol, pyruvic acid, quinic acid, rhamnose, ribose, saccharic acid, salicin, sarcosine, sorbose, succinic acid, sucrose, starch, trehalose and xylose.

$\dagger \mathrm{w}$, weak acid production; + , strong acid production.

type of chitinase enzyme (Welburn et al., 1993) and in this study we show that strain $\mathrm{M}^{\mathrm{T}}$ produces $\beta-N$ acetylglucosaminidase. Interestingly, chitinase production by this micro-organism has been postulated to account for an increase in trypanosome susceptibility in laboratory colonies of $G$. m. morsitans known to harbour large numbers of S-endosymbionts (Welburn $\&$ Maudlin, 1991). In addition to $\beta$ - $N$-acetylglucosaminidase, strain $\mathrm{M} 1^{\mathrm{T}}$ also produced $\alpha$-galactosidase.

\section{Carbon substrate assimilation tests}

Perhaps the most striking feature of strain $\mathrm{Ml}^{\mathrm{T}}$ was its unusual carbon substrate assimilation characteristics (Table 2). While strain $\mathrm{Ml}^{\mathrm{T}}$ did utilize and produce acid from glucose, both growth and acid production were more vigorous when either $N$-acetyl-D-glucosamine or raffinose was provided as a carbon source. These result are in agreement with the glycosidase detection tests, where it was found that strain $\mathrm{M}^{\mathrm{T}}$ produced $\alpha$-galactosidase (involved in raffinose catabolism) and $\beta$ - $N$-acetylglucosaminidase (involved in $N$-acetyl-D-glucosamine catabolism). Strain $\mathrm{M}^{\mathrm{T}}$ also used glycol chitosan, a polymer of $N$-acetyl-D-glucosamine, as a carbon source and this was accompanied by weak acid production. The sugar alcohols sorbitol and mannitol were also utilized by strain $M 1^{\mathrm{T}}$, and in both cases weak acid production was detected. This suggests that strain $\mathrm{M} 1^{\mathrm{T}}$ is devoted to the use of $N$-acetyl-D-glucosamine and raffinose as primary carbon sources. While polymerized $N$-acetyl-D-glucosamine (chitin) is known to form the exoskeleton and gut peritrophic membrane of tsetse flies (Lehane et al., 1996; Wigglesworth, 1972), little is known about the 
Sodalis glossinidius gen. nov., sp. nov.

presence of raffinose in this insect. In the maize weevil, Sitophilus zeamais, an insect known to harbour closely related S-endosymbionts, raffinose is known to be an important dietary component (Baker, 1991). In addition, the S-endosymbiont-carrying aphid Acyrthosiphon pisum (Chen \& Purcell, 1997; Unterman et al., 1989) and whitefly Bemisia tabaci (Costa et al., 1995) are known to produce honeydew rich in raffinose (Miller et al., 1994). In the case of the silver leaf whitefly Bemisia argentifolii, experiments involving aposymbiotic strains have shown that endosymbionts are capable of influencing the composition of honeydew (Davidson et al., 1994).

\section{Taxonomic position of strain M1 ${ }^{\top}$}

Phylogenetic analysis based on the 16S rDNA locus has revealed that the G. m. morsitans S-endosymbiont is most closely related to the S-endosymbiont found in Glossinia pallidipes, sharing an identical 16S rDNA sequence over 1117 bp (Beard et al., 1993b). In a more detailed study (Aksoy et al., 1995) it was shown that the S-endosymbiont of G. m. morsitans is also closely related to the S-endosymbionts found in Glossinia palpalis (pairwise distance over $1026 \mathrm{bp}, 1 \mathrm{bp}$ ), Glossinia austeni (pairwise distance over $1026 \mathrm{bp}$, $1 \mathrm{bp}$ ), Glossinia fuscipes (pairwise distance over $1026 \mathrm{bp}, 2 \mathrm{bp}$ ) and Glossinia brevipalpis (pairwise distance over $1026 \mathrm{bp}, 4 \mathrm{bp}$ ). In addition, it was shown that the S-endosymbiont of G. m. morsitans is also closely related to the S-endosymbionts of Sitophilus zeamais (pairwise distance over $940 \mathrm{bp}, 21 \mathrm{bp}$ ) and Acyrthosiphon pisum (pairwise distance over $940 \mathrm{bp}$, $54 \mathrm{bp}$ ). These studies suggest that a distinct lineage of S-endosymbionts exists within the family Enterobacteriaceae. It is known that the P-endosymbionts of insects (including G. m. morsitans) form a separate distinct lineage within the Enterobacteriaceae and recently the P-endosymbiont of $G . m$. morsitans has been assigned correct nomenclature as Wigglesworthia glossinidia (Aksoy, 1995). On the basis of the phylogenetic analyses and the distinctions presented in this study we propose a new genus, Sodalis gen. nov., for the closely related secondary symbiotic bacteria found in Glossina spp. In addition, we propose a new species, Sodalis glossinidius, for the S-endosymbiont found in $G$. $m$. morsitans and $G$. pallidipes, formerly known as the Rickettsia-like organism of tsetse. Phenotypic testing is required to determine the candidature of the other Glossina spp. S-endosymbionts and the Sendosymbiont of Sitophilus zeamais within the genus Sodalis.

\section{Description of Sodalis gen. nov.}

Sodalis (So'da.lis. M.L. masc. n. sodalis a companion).

The type species is Sodalis glossinidius. The essential characteristics of this genus are given in the description of $S$. glossinidius.

\section{Description of Sodalis glossinidius sp. nov.}

Sodalis glossinidius (glos.sin.i'dus. M.L. glossinidius of the genus Glossina).

The cells are non motile, non spore-forming, filamentous, Gram-negative rods $(2-12 \mu \mathrm{m}$ in length, $1-1.5 \mu \mathrm{m}$ in diameter), dividing by septation. The bacteria grow intracellularly in Aedes albopictus cell culture and can grow axenically in media containing enzymically digested proteins as nitrogen sources. They are microaerophilic and can only be cultivated on solid media with aerotolerance-enhancing supplements or under a reduced-oxygen atmosphere. Optimum atmospheric conditions for solid-phase culture are $5 \%$ oxygen, balanced with carbon dioxide. The optimum temperature for growth is $25^{\circ} \mathrm{C}$ with little or no growth at temperatures exceeding $30^{\circ} \mathrm{C}$. Negative for catalase, oxidase, DNase, gelatinase, urease, nitrate reductase, indole production, hippurate hydrolysis, arginine dihydrolase, lysine decarboxylase, ornithine decarboxylase, phenylalanine decarboxylase and starch hydrolysis. Produces $\alpha$-galactosidase and $\beta-N$ acetylglucosaminidase. Do not produce $\alpha$-fucosidase, $\beta$-galactosidase, $\alpha$-glucosidase, $\beta$-glucosidase, $\beta$-glucuronidase, $\alpha$-mannosidase and $\beta$-xylosidase. Utilizes $N$ acetyl-D-glucosamine and raffinose accompanied by a high level of acid production. Utilizes glucose, glycol chitosan, mannitol and sorbitol with accompanying weak acid production. No increase in growth is detected when any of the following carbon sources are incorporated in media: acetic acid, adonitol, $\delta$-amino valeric acid, L-arabinose, n-butanol, citric acid, dulcitol, ethanol, fructose, fumaric acid, galactose, glycerol, glycolic acid, histamine, $p$-hydroxybenzoic acid, $\alpha$-ketoglutaric acid, lactose, D, L-malic acid, maltose, mannose, melibiose, methyl- $\alpha$-D-glucopyranoside, myo-inositol, n-propanol, pyruvic acid, quinic acid, rhamnose, ribose, saccharic acid, salicin, sarcosine, sorbose, succinic acid, sucrose, starch, trehalose or xylose. The type strain is $\mathrm{Ml}^{\mathrm{T}}$, isolated from a laboratory colony of Glossinia morsitans morsitans. The bacterium is found in the midgut, fat body and haemolymph of $G . m$. morsitans. Strain $\mathrm{Ml}^{\mathrm{T}}$ has been deposited at the National Collection of Industrial and Marine Bacteria (Aberdeen, UK) under deposition NCIMB 13495.

\section{ACKNOWLEDGEMENTS}

This document is an output from a project funded by the Department for International Development (DFID) for the benefit of developing countries. The views expressed are not necessarily those of DFID.

\section{REFERENCES}

Aksoy, S. (1995). Wigglesworthia gen. nov. and Wigglesworthia glossinidia sp. nov., taxa consisting of the mycetocyte-associ- 
ated, primary endosymbionts of tsetse flies. Int $J$ Syst Bacteriol 45, 848-851.

Aksoy, S., Pourhosseini, A \& Chow, A. (1995). Mycetome endosymbionts of tsetse flies constitute a distinct lineage related to Enterobacteriaceae. Insect $\mathrm{Mol}$ Biol 4, 15-22.

Aksoy, S., Chen, X. \& Hypsa, V. (1997). Phylogeny and potential transmission routes of midgut-associated endosymbionts of tsetse (Diptera: Glossinidae). Insect Mol Biol 6, 183-190.

Aldhous, P. (1993). Bacteria may provide access to the tsetse fly. Science 261, 548.

Baker, J. E. (1991). Properties of glycosidases from the maize weevil, Sitophilus zeamais. Insect Biochem 21, 615-621.

Beard, C. B., O'Neill, S. L., Tesh, R. B., Richards, F. F. \& Aksoy, S. (1993a). Modification of arthropod vector competence via symbiotic bacteria. Parasitol Today 9, 179-183.

Beard, C. B., O'Neill, S. L., Mason, P., Mandelco, L., Woese, C. R., Tesh, R. B., Richards, F. F. \& Aksoy, S. (1993b). Genetic transformation and phylogeny of bacterial symbionts from tsetse. Insect Mol Biol 1, 123-131.

Bolton, F. J., Coates, D. \& Hutchinson, D. N. (1984). The ability of Campylobacter media supplements to neutralize photochemically induced toxicity and hydrogen peroxide. $J$ Appl Bacteriol 56, 151-7.

Buchner, P. (1965). Endosymbiosis of Animals with Plant Microorganisms. New York: Interscience.

Campbell, B. C., Bragg, T. S. \& Turner, C. E. (1992). Phylogeny of symbiotic bacteria of four weevil species (Coleoptera: Curculionidae) based on analysis of $16 \mathrm{~S}$ ribosomal DNA. Insect Biochem Mol Biol 22, 415-421.

Chen, D. Q. \& Purcell, A. H. (1997). Occurrence and transmission of facultative endosymbionts in aphids. Curr Microbiol 34, 220-225.

Clark, A., Baumann, L., Munson, M. A., Baumann, P., Campbell, B. C., Duffus, J. E., Osborne, L. S. \& Moran, N. A. (1992). The eubacterial endosymbionts of whiteflies (Homoptera: Aleyrodoidea) constitute a lineage distinct from the endosymbionts of aphids and mealybugs. Curr Microbiol 25, 119-123.

Costa, H. S., Westcot, D. M., Ullman, D. E., Rosell, R., Brown, J. K. \& Johnson, M. W. (1995). Morphological variation in Bemisia endosymbionts. Protoplasma 189, 194-202.

Cowan, S. T. (1974). Manual for the Identification of Medical Bacteria, 2nd edn. Cambridge, UK: Cambridge University Press.

Dale, C. (1997). The secondary ( $S$-) endosymbionts of Glossinia spp. $\mathrm{PhD}$ thesis. University of Liverpool, UK.

Davidson, E. W., Segura, B. J., Steele, T. \& Hendrix, D. L. (1994). Microorganisms influence the composition of honeydew produced by the silverleaf whitefly, Bemisia argentifolili. $J$ Insect Physiol 40, 1069-1076.

Douglas, A. E. (1989). Mycetocyte symbiosis in insects. Biol Rev 64, 409-434

Douglas, A. E. (1997). Parallels and contrasts between symbiotic bacteria and bacterial-derived organelles: evidence from Buchnera, the bacterial symbiont of aphids. FEMS Microbiol Ecol 24, 1-9.

Gimenez, D. (1964). Staining Rickettsiae in yolk-sac cultures. Stain Techn 39, 135-140.

Hill, P. D. S. \& Campbell, J. A. (1973). The production of symbiont-free Glossina morsitans and an associated loss of female fertility. Trans $R$ Soc Trop Med Hyg 67, 727-728.

Holt, J. G., Krieg, N. R., Sneath, P. H. A., Staley, J. T. \& Williams,
S. T. (editors) (1994). Bergey's Manual of Determinative Bacteriology, 9th edn. Baltimore: Williams \& Wilkins.

Huebner, E. \& Davey, K. G. (1974). Bacteroids in the ovaries of a tsetse fly. Nature 249, 260-261.

Hypsa, V. \& Aksoy, S. (1997). Phylogenetic characterization of two transovarially transmitted endosymbionts of the bedbug Cimex lectularius (Heteroptera: Cimicidae). Insect Mol Biol 6, 301-304.

Hypsa, V. \& Dale, C. (1997). In vitro culture and phylogenetic analysis of Candidatus Arsenophonus triatominarum an intracellular bacterium from the triatomine bug Triatoma infestans. Int J Syst Bacteriol 47, 1140-1144.

Igarashi, A. (1978). Isolation of Singh's Aedes albopictus cell clone sensitive to dengue and chikungunya viruses. J Gen Virol 40, 531 .

Krieg, N. R. \& Hoffman, P. S. (1986). Microaerophily and oxygen toxicity. Annu Rev Microbiol 40, 107-130.

Lehane, M. J., Allingham, P. G. \& Weglicki, P. (1996). Composition of the peritrophic matrix of the tsetse fly, Glossina morsitans morsitans. Cell Tissue Res 283, 375-384.

Maudlin, I. \& Ellis, D. S. (1985). Association between intracellular rickettsial-like infections of midgut cells and susceptibility to trypanosome infection in Glossina spp. Z Parasitenkd 71, 683-687.

Miller, W. B., Peralta, E., Ellis, D. R. \& Perkins, H. H. (1994). Stickiness potential of individual insect honeydew carbohydrates on cotton lint. Textile Res $J$ 64, 344-350.

Moat, A. G. \& Foster J. W. (1988). Microbial Physiology. New York: Wiley.

Munson, M. A., Baumann, P. \& Kinsey, M. B. (1991). Buchnera gen. nov. and Buchnera aphidicola sp. nov., a taxon consisting of the mycetocyte-associated, primary endosymbionts of aphids. Int J Syst Bacteriol 41, 566-568.

Nogge, G. (1976). Sterility in tsetse flies caused by loss of symbionts. Experientia 32, 995.

Nogge, G. (1978). Aposymbiotic tsetse flies, Glossina morsitans morsitans, obtained by feeding on rabbits immunised specifically with symbionts. $J$ Insect Physiol 24, 299-304.

Nogge, G. (1981). Significance of symbionts for the maintenance of an optimal nutritional state of successful reproduction in hematophagous arthropods. Parasitology 82, 101-104.

O'Neill, S. L., Giordano, R., Colbert, A. M. E., Karr, L. \& Robertson, H. M. (1992). 16S rRNA phylogenetic analysis of bacterial endosymbionts associated with cytoplasmic incompatibility in insects. Proc Natl Acad Sci USA 89, 2699-2702.

O'Neill, S. L., Gooding, R. H. \& Aksoy, S. (1993). Phylogenetically distant symbiotic microorganisms reside in Glossina midgut and ovary tissues. Med Vet Entomol 7, 377-383.

O'Neill, S. L., Pettigrew, M. M., Sinkins, S.P., Braig, H. R., Andreadis, T. G. \& Tesh, R. B. (1997). In vitro cultivation of Wolbachia pipientis in an Aedes albopictus cell line. Insect Mol Biol 6, 33-39.

Pinnock, D. E. \& Hess, R. T. (1974). The occurrence of intracellular rickettsia-like organisms in the tsetse flies, Glossina morsitans, G. fuscipes, G. brevipalpis and G. pallidipes. Acta Trop 31, 70-79.

Southwood, T. R. E., Khalaf, S. \& Sinden, R. E. (1975). The microorganisms of tsetse flies. Acta Trop 32, 259-266.

Unterman, B. M., Baumann, P. \& McLean, D. L. (1989). Pea aphid symbiont relationships established by analysis of $16 \mathrm{~S}$ rRNAs. J Bacteriol 171, 2970-2974. 
Welburn, S. C. \& Maudlin, I. (1991). Rickettsia-like organisms, puparial temperature and susceptibility to trypanosome infection in Glossina morsitans. Parasitology 102, 201-206.

Welburn, S. C., Maudlin, I. \& Ellis, D. S. (1987). In vitro cultivation of rickettsia-like organisms from Glossina spp. Ann Trop Med Parasitol 81, 331-335.
Welburn, S. C., Arnold, K., Maudlin, I. \& Gooday, G. W. (1993). Rickettsia-like organisms and chitinase production in relation to transmission of trypanosomes by tsetse flies. Parasitology 107, 141-145.

Wigglesworth, V. B. (1972). The Principles of Insect Physiology, 7 th edn. London: Chapman \& Hall. 